\title{
Influence of Personality Traits and Learning Styles on Undergraduate Medical Students' Academic Achievement
}

\author{
Enjy Abouzeid (1D' \\ Sally Fouad (D) \\ Nourhan F Wasfy (ID) \\ Rania Alkhadragy $\mathbb{D}^{\prime}$ \\ Mohamed Hefny (iD ${ }^{2}$ \\ Doaa Kamal (D) \\ 'Medical Education Department, Faculty \\ of Medicine, Suez Canal University, \\ Ismailia, Egypt; ${ }^{2}$ Department of Physica \\ Medicine, Rheumatology and \\ Rehabilitation, Faculty of Medicine, Suez \\ Canal University, Ismailia, Egypt
}

Purpose: Learning focus has shifted from conventional teacher-centered to student-centered; therefore, methods used to support and encourage learners must be considered. Meanwhile, the individual differences between learners should be taken into consideration by medical educators. Aiming to achieve a better learning experience, the current study investigates the relationship between personality traits and learning styles and their effect on students' academic achievement.

Subjects and Methods: An analytical, cross-sectional study, encompassing a sample of 333 undergraduate first-year medical students, at the Faculty of Medicine, Suez Canal University in Egypt was conducted. The Big Five personality traits test and VARK learning styles questionnaires were used to assess students' personality traits and learning styles, respectively, in the medical education module which is a part of the Foundation II module. The former is five weeks' duration and is followed by a summative exam at the end. Students' academic achievement was determined from their grades in Foundation II module by the end of the semester.

Results: Study findings generally indicate that the highest domain of learning styles among students is the kinesthetic domain. A statistically significant difference between males and females regarding their learning style preferences was detected. Also, there was a statistically significant relationship between auditory and kinesthetic learning styles and academic achievement. Though there was a significant relationship between kinesthetic learning style with both openness traits and academic achievement, no significant statistical relationship was found between any of the personality traits and academic achievement.

Conclusion: This study concludes that learning style could affect students' academic achievement. It reveals that the kinesthetic learning style is the most preferred learning style among our medical students, also the agreeableness and openness traits were the most common personality traits among them. No significant relationship was detected between personality traits and academic achievement.

Keywords: learning styles, personality traits, academic achievement, active learning, medical education

\section{Introduction}

Personality traits are the differences of individual characters in terms of pattern changes of cognition, behavior, and emotion. ${ }^{1}$ One of the most widely used systems in describing personality traits is the "Big Five". As stated by Costa et al (1992), personality can be depicted by five wide attribute measurements: Neuroticism, Agreeableness, Extroversion, Openness, and Conscientiousness. Neuroticism is
Correspondence: Nourhan F Wasfy Medical Education Department, Faculty of Medicine, Suez Canal University, Ismailia, Egypt

Email nourhan_f_wasfy@med.suez.edu.eg 
characterized by instability and is considered the polar opposite of emotional stability. Agreeableness is characterized by good-naturedness, cooperativeness, and trust. Extroversion is characterized by talkativeness, assertiveness, and energy. Openness is characterized by originality, curiosity, and ingenuity. Finally, conscientiousness is characterized by orderliness, responsibility, and dependability. ${ }^{2}$ According to McCrae and Costa's five-factor theory of personality, the Big Five personality traits represent part of a dynamic personality framework. Accordingly, it is critical to properly recognize the personality traits as they can influence learners' behavior which in turn can be compelling in their academic progress. ${ }^{3}$

On the other hand, learning styles are also different from one learner to another and each student has his/her specific attributes in learning and the method by which they can cope with the environment. Moreover, learning style is playing a major role in students' preference towards certain teaching approaches and learning environments. ${ }^{4}$ Learners consistently have the styles that they believe are reasonable for them to apply in their setting to help them acquire the best learning outcomes. ${ }^{5}$ Despite the wide variety of learning styles conceptual models, Neil Fleming's VARK model is one of the most commonly used models that was designed to help learners to learn better about their specific learning preferences. Fleming designed a tool in 1987 that proposed that there are four principal types of learners: visual, auditory, reading/writing, and kinesthetic. ${ }^{6}$ Visual learners learn through watching videos, images, and figures. Aural learners learn through listening to lectures; reading-writing learners learn through reading texts and writing notes on them, and kinesthetic learners learn through touch and manipulation of objects. $^{7}$

Various studies ${ }^{8-12}$ have examined the relationship between learning styles and academic achievement in students from different backgrounds. Controversial views were reported as some of these studies indicated a significant relationship between learning style and academic achievement, while others found no significant relationship. This discrepancy has raised the need for further investigation and study. ${ }^{13,14}$

The idea of examining the relationship between personality traits and learning styles is not a new one. ${ }^{15,16}$ Various studies have revealed that there is an association between learning styles and personality traits. ${ }^{17-19}$ Furthermore, studies have been conducted to determine the ability of both learning styles and personality traits and to decide the learning requirements. Moreover, other studies have explained the positive relationship of both of them with academic achievement. ${ }^{10,20}$

The Faculty of Medicine, Suez Canal University (FOM$\mathrm{SCU}$ ) formulated the undergraduate curriculum taking into consideration the performance standards of competent physicians. The curriculum development committee responded to the principles of students' self-learning skills and the biopsychosocial paradigm. The FOM-SCU has also adopted several innovative strategies including Problem-Based Learning and Community-Based Education which allow for integrating basic and clinical sciences and provide opportunities for early patient exposure. ${ }^{21}$

In the medical education context, few studies were conducted to examine the joint influence of learning styles and personality traits on academic achievement particularly in the pre-clerkship years. ${ }^{15}$ On the other hand, different studies were conducted in other different Health Professions Education, eg, Dental medicine, Nursing, and Midwifery. ${ }^{7,22}$

As the focus on learning has shifted from conventional teacher-centered to student-centered, the methods to support and encourage learners must be considered to foster better knowledge delivery. Thus, the individual differences between learners must be taken into consideration by medical educators. The current study is focusing on how personality traits and learning styles would affect the students' academic achievement.

We aim to improve the learning experience at our medical school. So, we have thought of providing congruence between teaching and learning future modalities and learners' needs targeting to achieve better outcomes. Therefore, we assume that examining the personality traits, the different learning styles, and their relation on students' academic achievement may lead to enrichment of their learning experience. Thus, our study raises the following research questions:

1. What are the types and frequencies of learning styles among our undergraduate medical students?

2. What are the types and frequencies of personality traits among our undergraduate medical students?

3 . Is there any gender difference concerning personality traits and Learning styles among our undergraduate medical students?

4. Is there any relationship between personality traits and Learning styles among our undergraduate medical students? 
5. How do personality traits and Learning styles affect academic achievement among our undergraduate medical students?

\section{Methodology Study Design}

A cross-sectional analytical study was conducted at the Faculty of Medicine, Suez Canal University, Egypt.

\section{Sample and Context}

The study population included a total comprehensive sample of the first-year medical students of the academic year 2019-2020. The sample was homogeneous in the average age interval, background as high school students, and field of study in which all the students were medical students in FOMSCU. However, the sample was heterogeneous in gender.

The total number of students in the first year was 437 . The inclusion criteria were willingness to participate in the study through filling the questionnaire and registering in the medical education module. The questionnaire was sent to all the students, but the response rate was 336 students with a response rate of $77 \%{ }^{24}$

The first-year students have been selected because they are experiencing a huge shift from school learning to medical education. Additionally, their homogeneous background as high school students and age may eliminate some confounders. Finally, the Faculty of Medicine, Suez Canal University is offering the medical education module during the first semester in the first year. This module is a part of the Foundation II module. The Medical Education module is delivered through the MOODLEC learning management platform. This module aims to help students improve their academic performance by introducing several important Medical Education topics. Learning styles and Personality traits were included in one of the module's tasks. The task was formulated to guide students in identifying their own learning style, personality traits and reflect on the results of the given questionnaires (Annex 1).

\section{Sample Size}

$\mathrm{N}=\{(\mathrm{Z} \alpha+\mathrm{Z} \beta) / \mathrm{C}\} 2+3^{23}$

\section{Where $\mathrm{N}=$ Sample size}

$\alpha$ (two-tailed) $=0.05$ (Threshold probability for rejecting the null hypothesis. Type I error rate).

$Z \alpha=1.9600$ (The standard normal deviate for $\alpha$ ) $\beta=0.20$ (Probability of failing to reject the null hypothesis under the alternative hypothesis. Type II error rate.)

$\mathrm{Z} \beta=0.8416$ (The standard normal deviate for $\beta$ )

$\mathrm{C}=0.5 * \ln [(1+\mathrm{r}) /(1-\mathrm{r})]=0.1511$

$\mathrm{r}=0.15$ (The expected correlation coefficient) ${ }^{10}$

So, according to the previous formula, the sample size will be 347 participants.

\section{Data Collection Tools Personality Traits}

The big five personality traits are the best accepted and most commonly used model of personality in academic psychology (https://www.truity.com/test/big-five-personality-test). The test was developed by Goldberg (1992) While there seem to be unlimited personality variables, five stand out from the pack in terms of explaining a lot of a person's answers to questions about their personality: Extroversion, Neuroticism, Agreeableness, Conscientiousness, and Openness to experience. The test consists of sixty items that must be rated on how true they are about you and how well they describe you on a five-point scale where $1=$ Inaccurate, $3=$ Neutral, and $5=$ Accurate. It takes most people 3-8 minutes to complete. ${ }^{25,26}$

\section{Learning Styles}

The VARK questionnaire is a standard tool, whose both validity and reliability were assessed and confirmed in a study by Zhu (2018). ${ }^{27}$ As the Arabic language is the students' first language, we used the Arabic version of VARK due to its simplicity, relative ease of implementation, average reliability, and validity. The VARK questionnaire consists of 16 multiple choice items and can be used to identify four types of learning styles. It has been validated for measuring learning preferences. ${ }^{28}$ Twenty-Five $\%$ of the studies that used the Arabic version of the VARK instrument verified its reliability and validity. ${ }^{29}$

Each item is related to a particular style. The respondents should choose the options according to their preferences, and if one choice does not reflect the whole view, they can choose more options and leave items that have not happened yet. The distribution of the VARK preferences was calculated according to the VARK website guidelines. ${ }^{30}$ Higher scores in each learning style indicate the respondents' greater desire for that style. Accordingly, learning preferences were categorized as unimodal $(\mathrm{V}, \mathrm{A}$, $\mathrm{R}$, or $\mathrm{K}$ ), If an individual gets equal scores in two styles his/ her learning style is considered bimodal (VA, VR, VK, 
$\mathrm{AR}, \mathrm{AK}$, and RK). While getting equal scores in three styles is considered trimodal. Getting equal scores in more than three styles, his/ her learning style is considered "multimodal". The total score in each item ranges from zero to 16 (Annex 2) ${ }^{6,27}$

\section{Academic Achievement}

The total scores of the medical students included in the study were collected. The scores represent their scores in one module (Foundation II). The module is five weeks' duration and is followed by a summative exam at the end. The scores were classified into four groups: A: more than or equal $85 \%$, B: $75-84 \%$, C: $65-74 \%$, D: $60-64 \%$, F: less than $60 \%$. The current study categorized the students according to their scores into three groups: high achievers (A \& B scores), borderline ( $\mathrm{C} \& \mathrm{D}$ scores), and low achievers' groups (F scores).

\section{Data Collection and Analysis}

The questionnaires were uploaded on the MOODLEC learning management platform under a Medical Education module. All the students have access to this platform. They completed them and results were collected by the authors in spreadsheets. The total scores were collected later at the end of the academic module then added to the same spreadsheet. Data were analyzed using Statistical Package for Social Science (version 27, SPSS Inc., Chicago, IL) using descriptive and inferential statistics. An independent sample $t$-test was utilized to determine differences in learning styles and personality traits among both genders. Then, Regression analysis and Pearson's Product-Moment Correlation analysis were performed to investigate the relationships between the study variables. The significance level was considered less than 0.05 .

\section{Ethical Considerations}

The Ethics Committee of the Suez Canal University approved the study. This study was conducted in accordance with the Declaration of Helsinki. Written informed consent was taken from all students and they were assured of the confidentiality of their information.

\section{Results}

The total number of students that responded to the questionnaire was 336. Students with missing data in the questionnaires were excluded. The final analysed sample was 333 undergraduate medical students, including 141 males and 192 females. The questionnaires showed fair reliability, Cronbach alpha for the VARK questionnaire was 0.6 while for the personality trait was 0.4

\section{Frequencies and Gender Differences}

Agreeableness was the highest personality trait in our study ( $M=69.6)$ followed by openness $(M=65.6)$, neuroticism $(\mathrm{M}=58.3)$, and conscientiousness $\mathrm{M}=(56.8)$. The least personality trait was extroversion $(M=53.7)$. Only one personality trait; Agreeableness showed a significant difference between male and female $t(5)=333, p<0.01$.

Regarding learning style, the highest was the Kinesthetic style (43\%) followed by the Auditory style $(30 \%)$ as seen in Figure 1. The students' learning styles are evenly distributed across Bimodal (31\%), Tri-modal (29\%), and Unimodal (27\%) styles. Only $13 \%$ of the students had a Multimodal style.

The frequencies of the students among the academic achievement categories showed that most of the students had B and C scores (Figure 2).

Pearson Chi-square showed a statistical significance difference between gender regarding the single and multimodal learning preferences $\chi^{2}(8)=84.63, p=0.00$ as

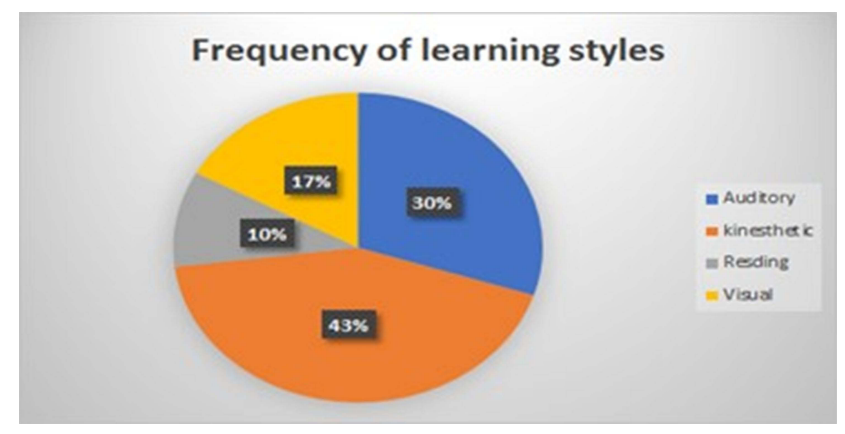

Figure I Frequency of single modal learning styles preferences among the undergraduate medical students.

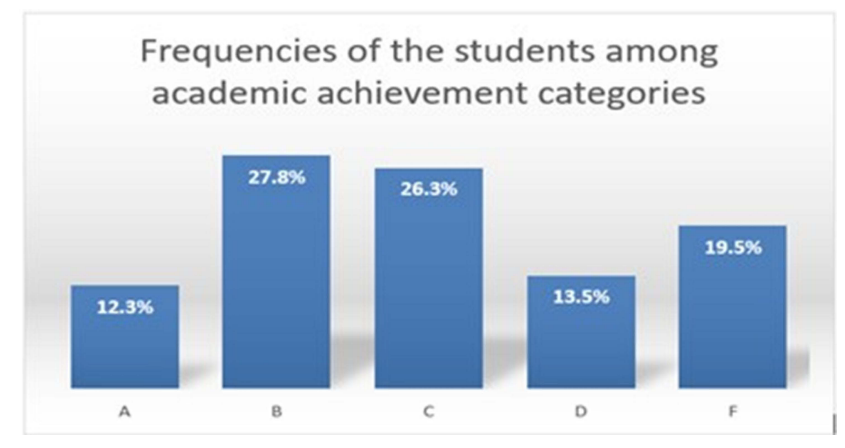

Figure 2 Frequency of the undergraduate medical students among the academic achievement categories. 
Table I Gender Difference Between Single and Multimodal Learning Styles*

\begin{tabular}{|c|c|c|c|c|c|c|}
\hline Gender & Unimodal & Bimodal & Trimodal & Multimodal & Total & Sig \\
\hline Female & $\begin{array}{l}48 \\
25.0 \%\end{array}$ & $\begin{array}{l}61 \\
31.8 \%\end{array}$ & $\begin{array}{l}59 \\
30.7 \%\end{array}$ & $\begin{array}{l}23 \\
12.0 \%\end{array}$ & 192 & \multirow[t]{2}{*}{0.000} \\
\hline Male & $\begin{array}{l}40 \\
28.4 \%\end{array}$ & $\begin{array}{l}42 \\
29.8 \%\end{array}$ & $\begin{array}{l}37 \\
26.2 \%\end{array}$ & $\begin{array}{l}20 \\
14.2 \%\end{array}$ & $|4|$ & \\
\hline
\end{tabular}

Note: ${ }^{*} p<0.05$.

Table 2 Relationship Between Gender and Students' Preferences Among Single Modal Learning Styles *

\begin{tabular}{|l|l|l|l|l|l|l|}
\hline Gender & Auditory & Kinesthetic & Reading/Writing & Visual & Total \\
\hline Female & 60 & 79 & 23 & 29 & 192 \\
& $31.3 \%$ & $41.1 \%$ & $12.0 \%$ & $15.1 \%$ & 0.000 \\
\hline Male & 39 & 63 & 10 & 27 & 141 \\
& $27.7 \%$ & $44.7 \%$ & $7.1 \%$ & $19.1 \%$ & \\
\hline
\end{tabular}

Note: $* p<0.05$.

shown in Table 1. Moreover, regarding the students' learning preference among single modal styles, the Chi-square test showed a statistically significant gender difference $\left(\chi^{2}\right.$ $(8)=86.65, \mathrm{p}=0.00)$ as shown in Table 2 .

\section{Correlation Analysis}

Correlation analysis indicated a number of significant relationships (as shown in Table 3). Openness was significantly related to two other personality traits; extroversion and agreeableness and two learning styles; visual and kinesthetic.

Conscientiousness was significantly related to two personality traits; agreeableness and neuroticism and one learning style; Reading. Finally, agreeableness was significantly related to neuroticism only.

The four learning styles were significantly related to each other. Auditory and Kinesthetic learning styles were significantly related to academic achievement.

\section{Relation with Academic Achievement}

Regarding the learning style used, Pearson Chi-square showed a significant difference between high and low achiever students $\left(\chi^{2}(8)=43.164, p=0.00\right)$ as shown in Table 4 . In terms of the number of learning styles used by the students, the results showed that the Kinesthetic style was predominantly preferred in both groups followed by the Auditory style. Additionally, the Trimodal was predominantly preferred in both the high and low achievers $\left(\chi^{2}\right.$ $(20)=57.945, \mathrm{p}=0.00)$ as shown in Table 5

\section{Discussion}

The current study tackled undergraduate medical students' different learning styles and personality traits and investigated the probable effect of the two factors on students' academic achievement.

This study provided some useful information, namely that medical students are more inclined to better learning when the learning process involves multiple practical aspects. This study's findings generally indicated that the highest domain of learning styles among students was the kinesthetic domain. This could be attributed to the early clinical exposure that our students encounter during their study throughout various educational strategies. This finding supported a previous study indicating that the kinesthetic learning style remained one of the favorite and preferred learning styles for the students in higher education. ${ }^{31}$ Kinesthetic and aural learning styles were also preferred among Pakistani dental students as indicated by Siddiqi et al (2012). ${ }^{32}$

The predominance of some particular learning styles in students can be related to gender differences. This is supported by our study findings that reported a statistically significant difference between males and females regarding the single and multi-modal learning preferences. In our study, most of the students preferred the unimodal and bimodal learning styles. Our students' preference of unimodal and bimodal learning styles could be attributed to their previous high school learning experience (including teaching styles and the type and nature of the educational contents) that is based on adopting only one learning style. ${ }^{14,33}$ 


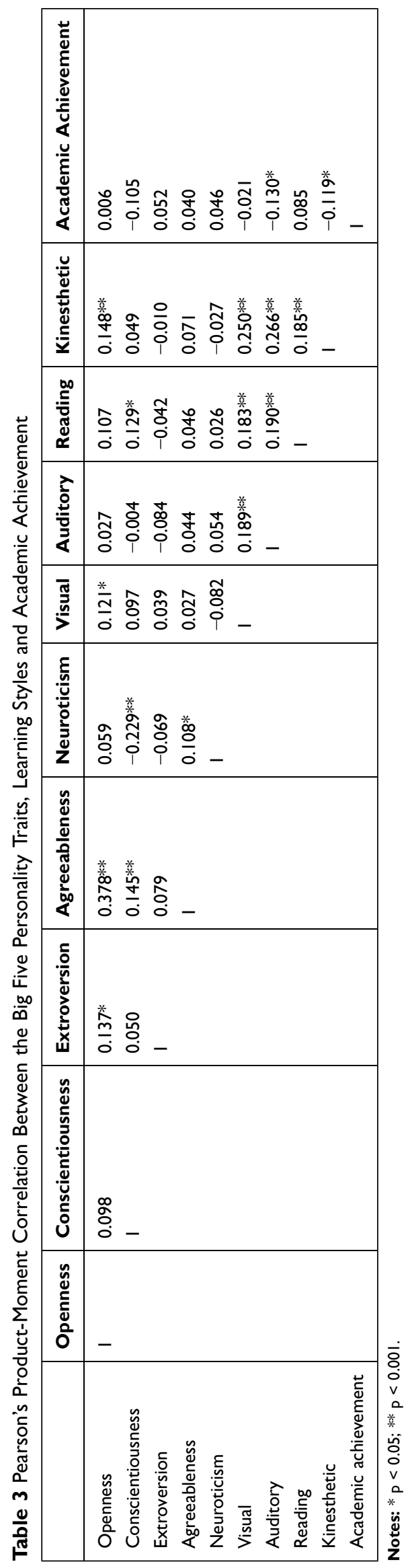

The previous findings are also consistent with those of Sarabi-Asiabar et al (2015) and Rezigalla et al (2019) who reported the domination of unimodal and bimodal learning styles. ${ }^{34,35}$ On the other hand, some studies reported that adult learners would prefer multimodal learning styles as they should know how to learn and can adjust to any method. This may raise a need for re-assessing the students' learning styles in advanced academic years. ${ }^{36,37}$

The improvement in academic achievement was further approved as there was a statistically significant relationship between auditory and kinesthetic learning styles and academic achievement. This could be attributed to the teaching and learning strategies adopted at our medical school as well as the content of our undergraduate curriculum which encourage the use of these specific learning styles and will eventually improve their academic achievement. The findings of this study are in accordance with those of the research carried out by Pellón et al (2013) in which students adopting kinesthetic learning styles tended to have the best grades. ${ }^{38}$

Furthermore, the results revealed that the most common personality traits among the medical students were agreeableness and openness. Students who are high in openness are abstract thinkers. Additionally, Openness was positively and significantly associated with two learning styles; visual and kinesthetic. Students with an openness type of personality enjoy new experiences, learn new things, and can think abstractly. Students with openness and kinesthetic learning style further illustrate a willingness to learn new things involving hands-on activities. This is supported by Moorman et al (2012), who reported that the personality type "openness" is the most common and is significantly related to auditory and visual, and kinesthetic learning styles. Students with agreeableness traits are said to put the needs of others ahead of their own needs as they tend to be altruistic, cooperative, and trusting. They are also able to work in a group. These personality traits are in concurrence with the learning strategies used in the school that encourage teamwork and experiential learning. ${ }^{39}$

Although there were significant relationships between kinesthetic learning style with both openness traits and academic achievement, there was no significant statistical relationship between any of personality traits and academic achievement. This finding may be explained by the presence of a mediator in this relationship or further research can be conducted using a different tool for assessing personality traits. ${ }^{10}$ This also could be supported by Laidra et al (2007), 
Table 4 Relationship Between Academic Achievement and Single Modal Learning Styles*

\begin{tabular}{|c|c|c|c|c|c|c|c|c|}
\hline & Auditory & Kinesthetic & Reading/Writing & Visual & Total & $\mathbf{x}^{2}$ & Df & Sig. \\
\hline Higher Achiever & 39 & 66 & II & 19 & 135 & 50.767 & 20 & 0.000 \\
\hline Borderline & 40 & 52 & 16 & 24 & 133 & & & \\
\hline Lower achiever & 20 & 24 & 6 & 13 & 65 & & & \\
\hline
\end{tabular}

Note: $* p<0.05$.

Table 5 Single and Multi-Modal Preferences According to Academic Achievement*

\begin{tabular}{|c|c|c|c|c|c|c|c|c|}
\hline & Unimodal & Bimodal & Trimodal & Multimodal & Total & $\mathbf{x}^{2}$ & df & Sig. \\
\hline Higher Achiever & 34 & 40 & 47 & 13 & 134 & 57.945 & 20 & 0.000 \\
\hline Borderline & 40 & 44 & 26 & 22 & 132 & & & \\
\hline Lower achiever & 14 & 19 & 22 & 8 & 63 & & & \\
\hline
\end{tabular}

Note: $* p<0.05$.

who argued that academic performance is difficult to be predicted by the broad Big Five personality traits. ${ }^{40}$ In contrast with our study, other studies Köseoglu in his study emphasized the joint influence of personality and learning styles on academic success. ${ }^{41}$ Meanwhile, Marcela worked in the same dilemma, but it was worth mentioning that he did not link with learning styles, instead, he used the learning strategies and reported a significant relationship between learning strategies (Deep Processing, Elaborative Processing, Fact Retention, Methodical Study), academic achievement and positive relation with personality traits Openness, Conscientiousness with academic achievement of university students. ${ }^{42}$

Moreover, the conscientiousness personality traits were significantly related to the reading learning style. A conscientious personality style student is dependable, organized, extremely reliable, hard worker, planner, and tends to be a high achiever student. He can control, direct and regulate his own emotions to work towards goals and also plan effectively to achieve a high level of success. Therefore, the student is able to control themselves and works very hard to achieve their targets. Reading learning style prefers to read the study materials from organized text to convey information, notes, e-book, and books. These students are willing to read their notes and write all important things during the revision. They are also well-organized with their schedule. This finding is supported by Komarraju et al (2011) study who conducted a study among 308 undergraduates to test the relationship between personality and learning styles and found that conscientiousness and agreeableness have a positive relationship with all types of learning styles. ${ }^{10}$

\section{Limitations of the Study}

The present study had some limitations. Since the current study is cross-sectional in design, it was not possible to investigate the likelihood of a cause-and-effect relationship between learning style and academic achievement. The self-report method used to collect data in the current study might affect the accuracy of the results. The study is conducted in a single institution which may hinder the generalizability of the results.

\section{Conclusion}

This study added a new evidence about the importance of learning styles in medical education as they affect the students' academic achievement. The study revealed that the Kinesthetic learning style is the most preferred learning style, and the agreeableness and openness traits were the most common personality traits among our undergraduate medical students. Additionally, there was no statistically significant relationship between personality traits and academic achievement among the study sample.

\section{Practical Points}

- Educators should be aware of students' learning style preferences and their personality traits when designing course delivery strategies.

- The designed strategies have to combine a variety of methods to address different learning styles and include the different personality traits.

- Increasing the frequency of Kinesthetic activities in developed curricula. 
- Constructing learning environments that are supportive to learners' differences.

\section{Abbreviations}

FOM-SCU, Faculty of Medicine- Suez Canal University; PBL, Problem-Based Learning; CBE, Community-Based Education.

\section{Data Sharing Statement}

The datasets used and/or analysed during the current study are available from the corresponding author on reasonable request.

\section{Acknowledgments}

A special thanks go to Suez Canal university stakeholders at the faculty of Medicine as well as students who participated in this study.

\section{Funding}

This research received no specific grant from any funding agency in the public, commercial, or not-for-profit sectors.

\section{Disclosure}

The authors report no conflict of interest in this work.

\section{References}

1. Hogan R, Hogan J, Roberts BW. Personality measurement and employment decisions: questions and answers. Am Psychol. 1996;51(5):469. doi:10.1037/0003-066X.51.5.469

2. Costa PT, McCrae RR. Neo Personality Inventory-Revised (NEO PIR). Odessa, FL: Psychological Assessment Resources; 1992.

3. McCrae RR, Costa PT. A five-factor theory of personality. In: Pervin LA, John OP, editors. Handbook of Personality: Theory and Research. New York: The Guilford Press; 1999:139-153.

4. Witkin HA. The role of cognitive style in academic performance and in teacher-student relations 1 2. ETS Research Bulletin Series. 1973;1973(1):i-58. doi:10.1002/j.2333-8504.1973.tb00450.x

5. JilardiDamavandi A, Mahyuddin R, Elias H, Daud SM, Shabani J. Academic achievement of students with different learning styles. Int J Psychol Stud. 2011;3(2):186-192. doi:10.5539/ijps.v3n2p186

6. Fleming ND, Mills C. Helping students understand how they learn. The Teaching Professor. 1992;7(4):44-63.

7. Mozaffari HR, Janatolmakan M, Sharifi R, Ghandinejad F, Andayeshgar B, Khatony A. The relationship between the VARK learning styles and academic achievement in Dental Students. $A d v$ Med Educ Pract. 2020;11:15. doi:10.2147/AMEP.S235002

8. Farajollahi M, Najafi H, Nosrati Hashi K, Najafiyan S. Relationship between learning styles and academic achievement of university students. Educ Strateg Med Sci. 2013;6(2):83-88.

9. Rashidi Z, Moghadami M. The relationship between learning styles with academic achievement and creativity of students in the senior department of education, psychology and social sciences, Islamic Azad University Roudehen Branch. ICHS. 2017;7(2):1-38.

10. Komarraju M, Karau SJ, Schmeck RR, Avdic A. The Big Five personality traits, learning styles, and academic achievement. Pers Individ Differ. 2011;51(4):472-477. doi:10.1016/j.paid.2011.04.019
11. Ruffing S, Wach F, Spinath FM, Brünken R, Karbach J. Learning strategies and general cognitive ability as predictors of gender-specific academic achievement. Front Psychol. 2015;6:1238. doi:10.3389/fpsyg.2015.01238

12. Li YS, Yu WP, Liu CF, Shieh SH, Yang BH. An exploratory study of the relationship between learning styles and academic performance among students in different nursing programs. Contemp Nurse. 2014;48(2):229-239. doi:10.1080/10376178.2014.11081945

13. Almigbal TH. Relationship between the learning style preferences of medical students and academic achievement. Saudi Med J. 2015;36 (3):349. doi:10.15537/smj.2015.3.10320

14. Liew SC, Sidhu J, Barua A. The relationship between learning preferences (styles and approaches) and learning outcomes among pre-clinical undergraduate medical students. BMC Med Educ. 2015;15(1):1-7. doi:10.1186/s12909-015-0327-0

15. Fallan L. Quality reform: personality type, preferred learning style and majors in a business school. Qual High Educ. 2006;12 (2):193-206. doi:10.1080/13538320600916817

16. Ibrahimoglu N, Unaldi I, Samancioglu M, Baglibel M. The relationship between personality traits and learning styles: a cluster analysis. AJMSE. 2013;2(3):93-108.

17. Salehi E, Hedjazi Y, Mahmood S. The effect of personality types on the learning styles of agricultural students (A case study in Iran). TOJNED. 2014;4(2):126-135.

18. Kim M, Roh S, Ihm J. The relationship between non-cognitive student attributes and academic achievements in a flipped learning classroom of a pre-dental science course. Korean J Med Educ. 2018;30(4):339. doi:10.3946/kjme.2018.109

19. Siddiquei N, Khalid R. The relationship between personality traits, learning styles and academic performance of e-learners. Open Praxis. 2018;10(3):249-263. doi:10.5944/openpraxis.10.3. 870

20. Khan A, Shin H, Sanil H, Sabil S. Effect of personality traits and learning styles towards students' academic achievement in Johor Bahru. IJET. 2018;7(2.10):4. doi:10.14419/ijet.v7i2.10.10 943

21. Hosny S, El Wazir Y, El Kalioby M, Farouk O, Ghaly M. Role of Suez Canal university, faculty of medicine in Egyptian medical education reform. Health Prof. Educ. 2016;2(1):44-50. doi:10.1016/ j.hpe.2016.01.007

22. Ghahremani Z, Amini K, Aghvamy M, Roohani M. Relationship between personality traits, learning styles and academic achievement among students of nursing and midwifery. J Nurs Educ. 2016;4 (4):52-62.

23. Hulley S, Cummings S, Browner W, Grady D, Newman T. Designing Clinical Research. Vol. 4th. Philadelphia: LWW; 2013.

24. Fincham JE. Response rates and responsiveness for surveys, standards, and the Journal. Am. J. Pharm. Educ. 2008;72:2.

25. Goldberg LR. The development of markers for the Big-Five factor structure. Psychol Assess. 1992;4(1):26.

26. Hee OC. Validity and reliability of the big five personality traits scale in Malaysia. IJIAS. 2014;5(4):309.

27. Zhu HR, Zeng $\mathrm{H}$, Zhang $\mathrm{H}$, et al. The preferred learning styles utilizing VARK among nursing students with bachelor degrees and associate degrees in China. Acta Paul Enferm. 2018;31(2):162-169. doi:10.1590/1982-0194201800024

28. Leite WL, Svinicki M, Shi Y. Attempted validation of the scores of the VARK: learning styles inventory with multitrait-multimethod confirmatory factor analysis models. Educ Psychol Meas. 2010;70 (2):323-339. doi:10.1177/0013164409344507

29. AlQahtani N, AlMoammar K, Taher S, AlBarakati S, AlKofide E. Learning preferences among dental students using the VARK questionnaire: a comparison between different academic levels and gender. J Pak Med Assoc. 2018;68(1):59-64.

30. VARK: a guide to learning styles. Available from: http://vark-learn. com/. Accessed May 6, 2021. 
31. Afzaal S, Siau NZ, Suhali WS. Evaluating students' personality and learning styles in higher education: pedagogical considerations. Int J Learn Teach Educ Res. 2019;145-164. doi:10.26803/IJLTER. 18.7.10

32. Siddiqi KM, Qazi HS, Khurram MS, Farooq U. Learning preferences of dental students at Islamabad Medical and Dental College. PODJ. 2012;32:2.

33. Kumar BJ, Sushma S, Naresh K, Kumarm B, Ajay S, Kirti S. Difference in learning style preference of medical, dental and B Pharma students. Int J Med Med.Sci. 2011;1(2):38-41.

34. Sarabi-Asiabar A, Jafari M, Sadeghifar J, et al. The relationship between learning style preferences and gender, educational major and status in first year medical students: a survey study from iran. Iran Red Crescent Med J. 2015;17(1).

35. Rezigalla AA, Ahmed OY. Learning style preferences among medical students in the College of Medicine, University of Bisha, Saudi Arabia (2018). Adv Med Educ Pract. 2019;10:795. doi:10.2147/ AMEP.S219176

36. Khan AK, Khan KR, Bashir Z, Hanif A. Learning style preferences among students of medical and dental colleges. AHPE. 2015;(1):1.
37. Chaudhry NA, Ashar A, Ahmad SA. Association of Visual, Aural, Read/ Wite,And Kinesthetic (VARK) learning styles and academic performances of dental students. PAFMJ. 2020;70(Suppl-1):S58-63.

38. Pellón M, Nome S, Arán A. Relationship between learning styles and academic performance of fifth graders enrolled in the medical course. Rev Bras Oftalmol. 2013;72(3):181-184. doi:10.1590/S0034-7280 2013000300008

39. Moorman D, Clark K. Student learning style and personality types: their implications for teaching. SoTL Commons Conference. 2012 https://digitalcommons.georgiasouthern.edu/sotlcommons/SoTL/ 2012/33. Accessed June 26, 2021.

40. Laidra K, Pullmann H, Allik J. Personality and intelligence as predictors of academic achievement: a cross-sectional study from elementary to secondary school. Pers Individ Differ. 2007;42(3):4 $41-451$.

41. Köseoglu Y. To what extent can the big five and learning styles predict academic achievement. JEP. 2016;7(30):43-51.

42. Marcela V. Learning strategy, personality traits and academic achievement of university students. Procedia Soc Behav. 2015;12 (174):3473-3478.

\section{Publish your work in this journal}

Advances in Medical Education and Practice is an international, peerreviewed, open access journal that aims to present and publish research on Medical Education covering medical, dental, nursing and allied health care professional education. The journal covers undergraduate education, postgraduate training and continuing medical education including emerging trends and innovative models linking education, research, and health care services. The manuscript management system is completely online and includes a very quick and fair peer-review system. Visit http://www.dovepress.com/testimonials.php to read real quotes from published authors.

Submit your manuscript here: http://www.dovepress.com/advances-in-medical-education-and-practice-journal 